\section{Electron microscopy}

studies of the thermal

stability of gold

\section{nanoparticle arrays}

Roger Ristau*, Ramchandra Tiruvalam, Patrick L. Clasen, Edward P. Gorskowski**, Martin P. Harmer and Christopher J. Kiely",Center for Advanced Materials and Nanotechnology, Lehigh University, 5 East Packer Avenue, Bethlehem, PA 18015-3195, USA. Irshad Hussain ${ }^{* * *}$ and Mathias Brust Center for Nanoscale Science, Department of Chemistry, University of Liverpool, Liverpool, Merseyside, L69 3BX, UK.

* Now at: Institute of Materials Science, University of Connecticut, Storrs, CT 06269, USA.

** Now at: Naval Research Laboratory, Multifunctional Materials Branch, Washington, DC 20375, USA.

*** LUMS School of Science and Engineering (SEE), D.H.A. Lahore Cantt - 54792, Pakistan.

\# Corresponding author; E-mail: chk5@lehigh.edu Phone: (610) 7584291

\section{Abstract}

A series of monolayer protected gold nanoparticle colloidal solutions have been prepared with average sizes in the $2-15 \mathrm{~nm}$ range. If a drop of such a colloidal suspension is deposited onto a $\mathrm{Si}_{3} \mathrm{~N}_{4}$ substrate and the solvent allowed to evaporate, the particles have a tendency to self-assemble into monolayer rafts with varying degrees of structural order depending on the initial mono-dispersity of the particles. The thermal stability of these selfassembled gold nanoparticle rafts as a function of particle size, heating method, heating rate and ligand identity have been assessed in this study. In-situ TEM studies show that sub-8nm Au nanoparticles on $\mathrm{Si}_{3} \mathrm{~N}_{4}$ have a tendency to coarsen upon slow heating, whereas those comprised of larger particles exhibit densification. Increasing the heating rate for the smaller particles promoted densification, forcing them to form highly interconnected string-like structures. Finally, rafts of sub-4nm alkanethiol protected Au nanoparticles are shown to sinter spontaneously under ambient conditions at room temperature on the timescale of several months. This unexpected effect may have important implications for the long term structural stability of any device constructed from sub- $4 \mathrm{~nm}$ gold nanoparticles.

\section{Introduction}

To date the most successful approaches to nanoscale manipulation have been based on electron beam lithography [1] and scanning probe microscopy [2, 3]. Unfortunately these methods are relatively expensive, serial in nature, and are not readily applicable to the mass production of nanoengineered materials. The ability to reproducibly produce ordered nanostructures on a larger scale by inexpensive chemical methods is therefore of great practical importance $[4,5]$, especially if the promised potential benefits of nanotechnology are to be exploited in the next generation of consumer devices, chemical sensing devices and magnetic recording media. One of the most straightforward approaches for constructing ordered nanoparticulate superstructures is by drop-cast self-assembly, whereby a colloidal suspension of sterically stabilized nanoparticles is introduced at a substrate surface and the carrier medium allowed to evaporate in a controlled fashion. For particles with a sufficiently narrow monomodal size distribution, well-defined packing order tends to develop in monolayer films [6-11]. One of the most commonly used nanomaterials being exploited for this particular purpose are alkanethiol protected gold nanoparticles $[6,12]$.

An important factor which has received relatively scant attention to date is the thermal stability of such self-assembled nanoparticulate materials. Thiol-derivatised Au clusters are known to be stable in toluene for periods of many years. However, when the solvent is evaporated off and the particles are crystallized onto a substrate, the structural stability of the particles can be deliberately compromised. For instance, subjecting the particles to intense electron beam irradiation in the TEM can be sufficient to disrupt the protective alkanethiol coating [13]. Once this has occurred it becomes energetically favorable for the Au particles to reduce their surface energy by sintering. Alternatively, nanostructure destabilization may unexpectedly occur due to variations in ambient environmental storage conditions (e.g. elevated temperature, or exposure to solvent vapors) which may potentially disturb the protective ligand environment that are separating neighboring nanoparticles. The destabilization and sintering of these self-assembled structures can therefore be considered as a desirable or an adverse phenomenon depending on the particular circumstances. In many cases, where it is imperative to preserve the integrity of the nanoparticles within the self-assembled structure in order to exploit the size-dependant properties of its constituents in a 


\section{Figure 1}
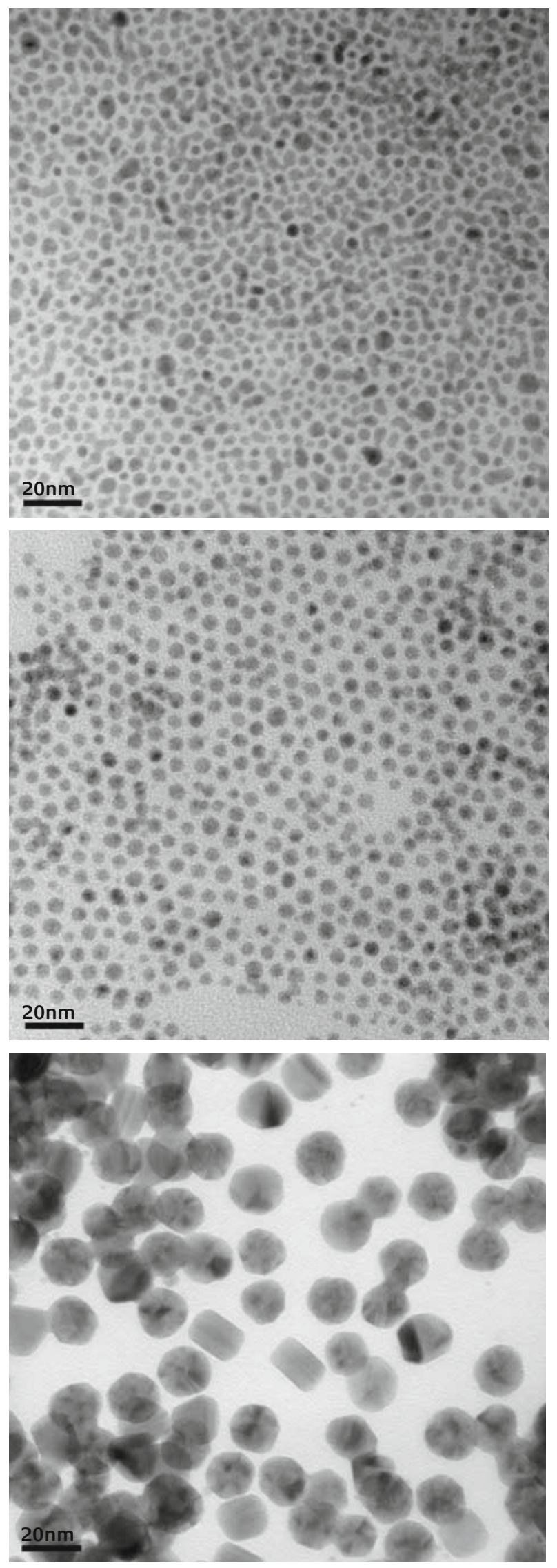

\section{$4 \mathrm{~nm}$}

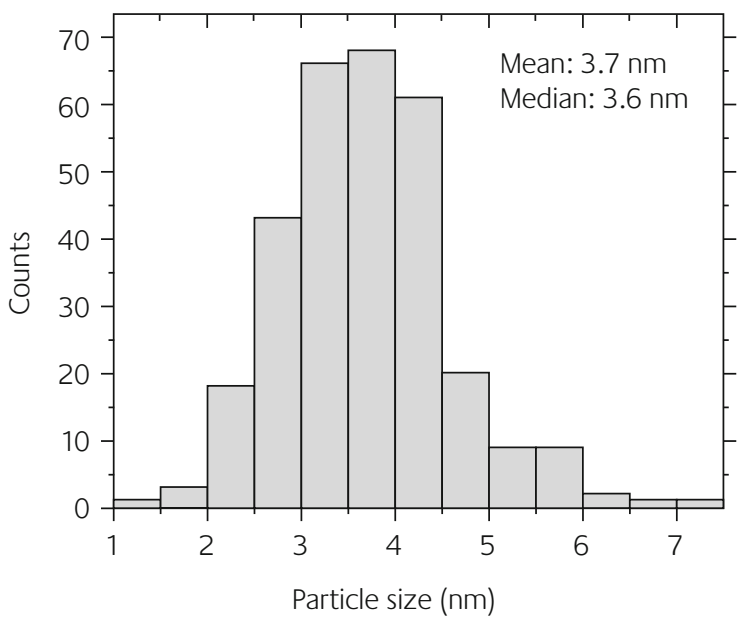

$5 \mathrm{~nm}$

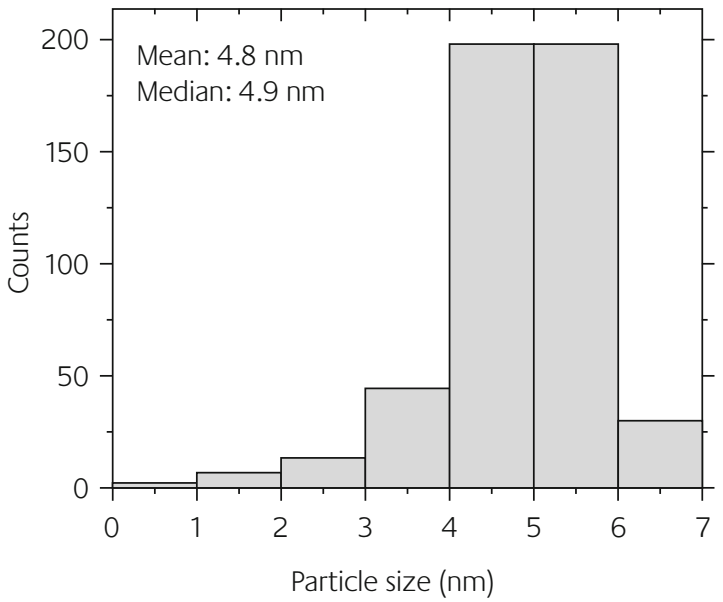

$15 \mathrm{~nm}$

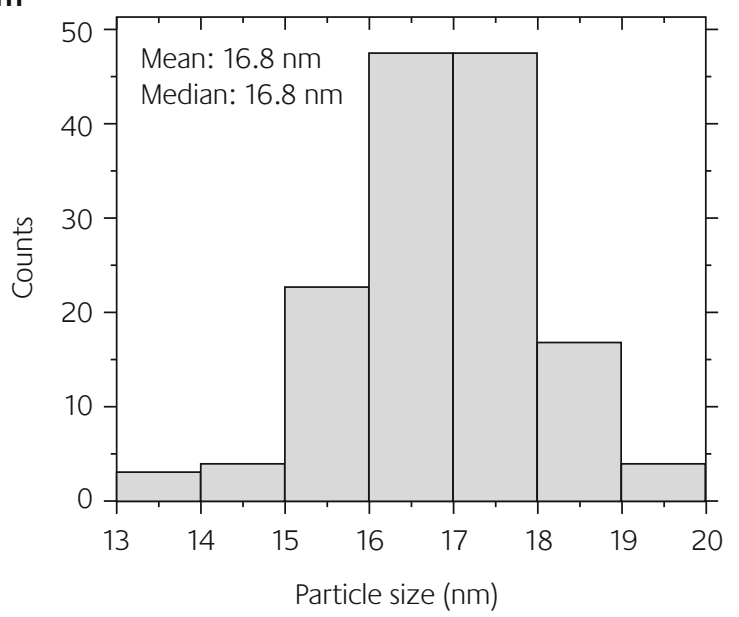

Representative transmission electron micrographs and corresponding histograms of particle size distribution for the nominal 4, 5 and 15nm preparations of Au nanoparticles 
device, sintering will be a destructive nuisance. In other situations, where it may be beneficial to deliberately destabilize the self-assembled particles to form features such as nanowires, multilayer stacks or complex nanopatterns, sintering can be considered as a controllable processing step in a nano-manufacturing process $[14,15]$. Being able to control both these scenarios depends on developing a basic understanding of the way in which nanoparticles held in such close proximity will sinter under a range of processing or storage conditions. In this paper we report some basic experiments to observe sintering phenomena for arrays of ligand stabilized gold nanoparticles in the $2-15 \mathrm{~nm}$ size range.

Buffat and Borel have performed fundamental studies to determine the size-dependence of the melting point of bare gold nanoparticles $[16,17]$. They used a heating stage in a transmission electron microscope and estimated the nanoparticle melting point from the temperature at which electron diffraction rings, and hence crystalline structure, disappeared. This pioneering work led to significant activity in studying the thermodynamics of melting of bare nanoparticles [18-20]. A number of subsequent in-situ transmission electron microscopy studies have also shed light of the structural stability [13, 21], evaporation [22] and coalescence [23, 24] characteristics of randomly arranged bare Au nanoparticles on carbon, HOPG and silica support films. These coalescence studies in particular have spawned a number of papers [24-29] where molecular dynamics calculations have been used to model the coalescence behavior of touching gold nanoparticles with clean surfaces.

In this work we have made a series of stock Au nanoparticle preparations in the range 2-15 $\mathrm{nm}$ and self-assembled them into two-dimensional arrays. We have then studied their destabilization and sintering behavior as a function of particle size and heating rate. A size regime is also identified where nanoparticles have a propensity to sinter spontaneously under dry ambient conditions at room temperature.

\section{Experimental}

Stock toluene solutions of dodecane-thiol capped Au nanoparticles of well-defined sizes (nominally 2, 3, 4, 5 \& 8 $\mathrm{nm}$ ) were prepared using a well-established synthesis method $[30,12]$. For each stock solution, TEM images were acquired and histograms of nanoparticle sizes were generated in order to confirm that our target average particle size had been produced (see Figure 1). In addition, a solution of $15 \mathrm{~nm}$ diameter Au nanoparticles were prepared in water by an acrylate reduction method developed at the University of Liverpool [31].

$\mathrm{Si}_{3} \mathrm{~N}_{4}$ membranes were used as electron transparent supports for the nanoparticles since in sintering experiments they gave more easily interpretable results than those supported on conventional carbon thin films. For the latter type of membranes there are strong secondary Van der Waals type interactions between the rough amorphous $C$ surfaces of a TEM support grid and the $C_{10}$ hydrocarbon chains that make up the protective ligand molecules around the nanoparticles. Furthermore, the continuous $C$ films were prone to carbon loss, perforation and eventual disintegration during heating experiments above $200^{\circ} \mathrm{C}$, whereas the $\mathrm{Si}_{3} \mathrm{~N}_{4}$ membranes were found to be much more robust at elevated temperatures. The nanoparticle assemblies were examined in either a Philips 420T TEM operating at $120 \mathrm{kV}$ or a JEOL 2000FX TEM operating at 200kV. A number of nanoparticle sintering methods were explored during the course of this work including, ex-situ furnace heating, ex-situ plasma heating, in-situ electron beam irradiation and in-situ conductive heating in a Philips annular TEM heating stage. Thermo-gravimetric analysis (TCA) studies were carried out using a Netzsch STA409 system.

\section{Results and discussion}

In order to investigate whether or not we were dealing with the sintering behavior of clean or ligand capped nanoparticles in our experiments some thermogravimetric analysis (TCA) measurements were carried out on a series of dried $\mathrm{Au}$ nanoparticles of various sizes to determine the temperature at which ligand de-stabilization occurred. Figure 2 shows comparative TGA traces for the $5 \mathrm{~nm}$ and $15 \mathrm{~nm} \mathrm{Au}$ nanoparticle preparations respectively. The 2, 3, 5 and $8 \mathrm{~nm}$ particles, which were all dodecane-thiol capped, showed very

\section{Figure 2}

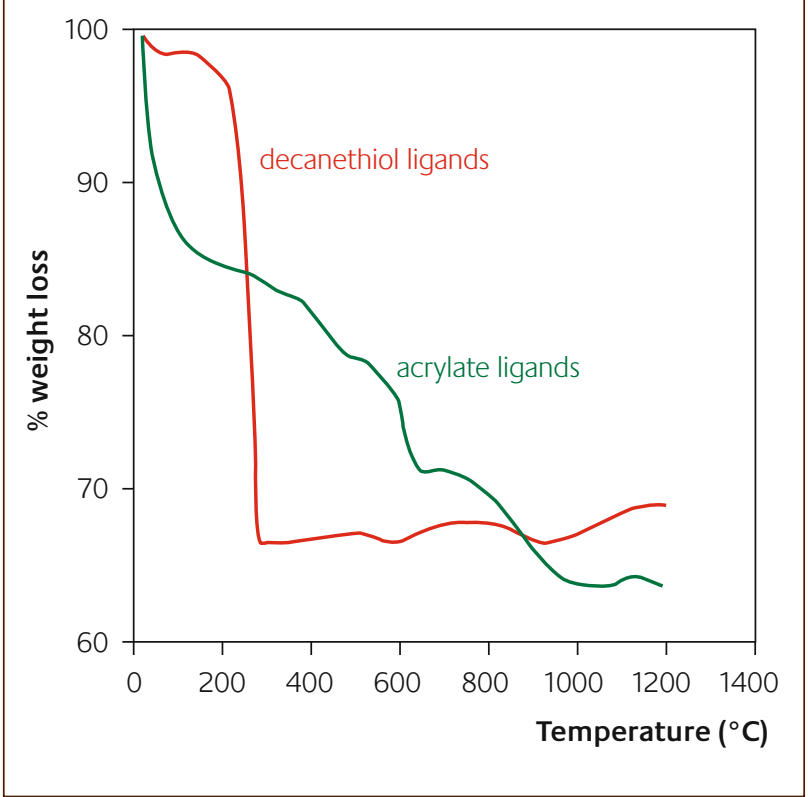

Comparative TGA traces obtained from $5 \mathrm{~nm}$ dodecane-thiol capped Au nanoparticles and 15nm sodium acrylate capped Au nanoparticles 


\section{Figure 3}

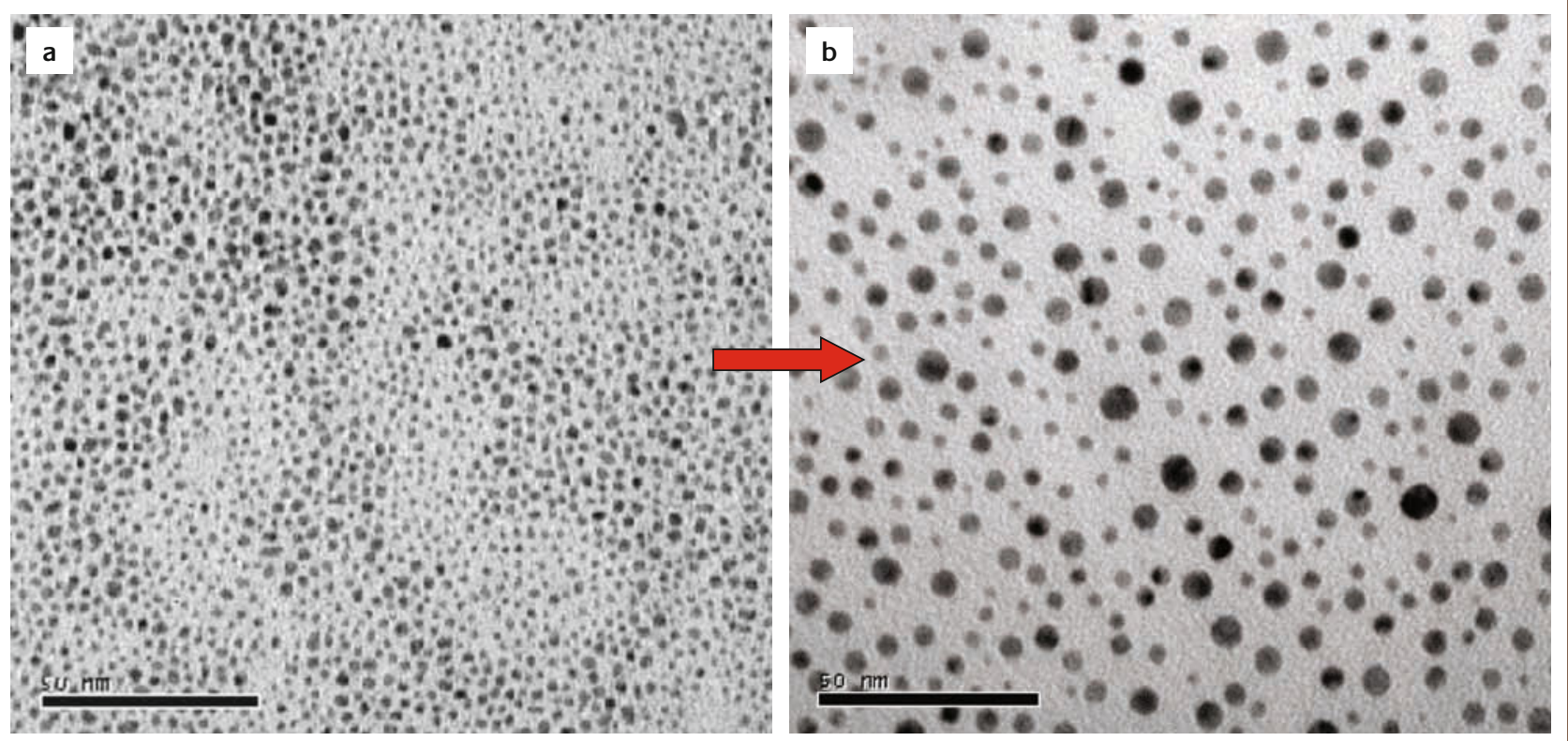

C

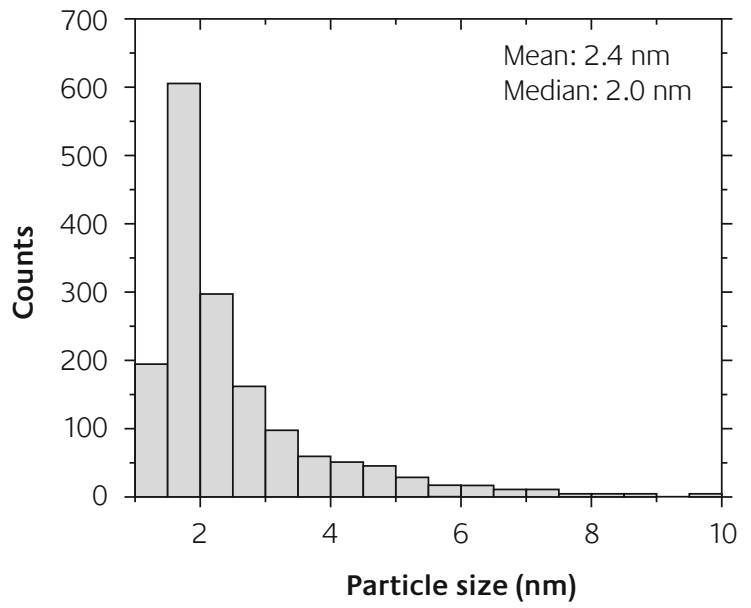

d

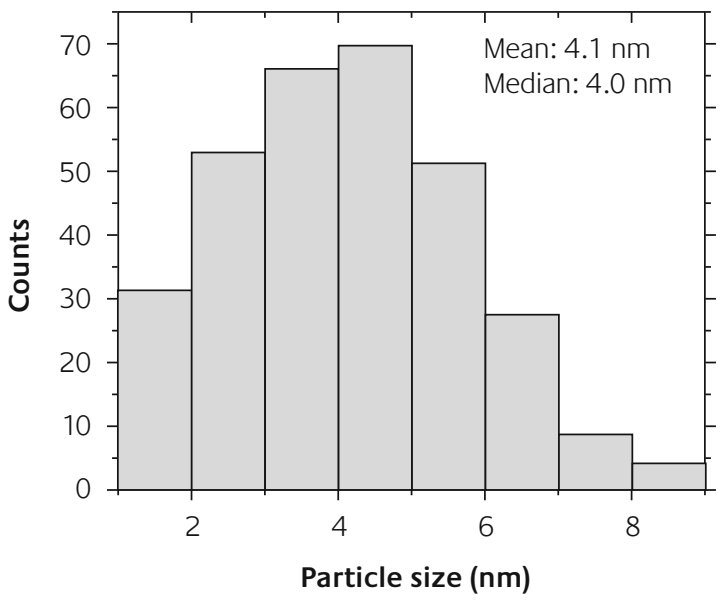

$2 \mathrm{~nm}$ particles supported on $\mathrm{Si}_{3} \mathrm{~N}_{4}$ (a) before and (b) after sintering [for 10 minutes at $250 \pm 20^{\circ} \mathrm{C}$ in an annular TEM heating stage] showing classic coarsening behavior. The corresponding particle size distributions before and after sintering are shown in (c) and (d) respectively

similar behavior with a very small weight loss $(<2 \%)$ around $100^{\circ} \mathrm{C}$ due to the desorption of water followed by a much more significant and sharp weight loss (about 33\% for the $5 \mathrm{~nm}$ preparation) in the range $220-260^{\circ} \mathrm{C}$ that corresponds to the clean desorption of the protective ligands as dithiol entities. This desorption behavior is consistent with previous TGA studies [32-34] where maximal ligand loss was noted at $\sim 250^{\circ} \mathrm{C}$, close to the boiling range $\left(266-283^{\circ} \mathrm{C}\right)$ of neat dodecane-thiol. The $15 \mathrm{~nm}$ particles on the other hand showed a slow gradual weight loss over the entire $100-1000^{\circ} \mathrm{C}$ temperature range which corresponds to a much more gradual desorption of the protective sodium acrylate groups. Hence we can be confident that our Au nanoparticles up to $8 \mathrm{~nm}$ in diameter are clean if heated above $250^{\circ} \mathrm{C}$, but the $15 \mathrm{~nm}$ particles always contained residual ligands on their surfaces at the sintering temperatures used in our experiments.

Samples consisting of the smallest nanoparticles supported on $\mathrm{Si}_{3} \mathrm{~N}_{4}$, such as the $2 \mathrm{~nm}$ particles shown before sintering in Figure 3(a), were observed to coarsen during in-situ sintering (i.e. some larger particles grow at the expense of smaller ones). Figure 3(b) shows an image of the $2 \mathrm{~nm}$ sample after $\sim 10$ minutes of sintering at $250 \pm 20^{\circ} \mathrm{C}$ in the annular TEM heating stage. Clearly the mean and median particle size increased to $\sim 4 \mathrm{~nm}$ while the total number of particles dramatically decreased. The corresponding particle size distributions are shown in Figure 3(c) and (d) respectively, where it is apparent that the shape of the distribution has 


\section{Figure 4}

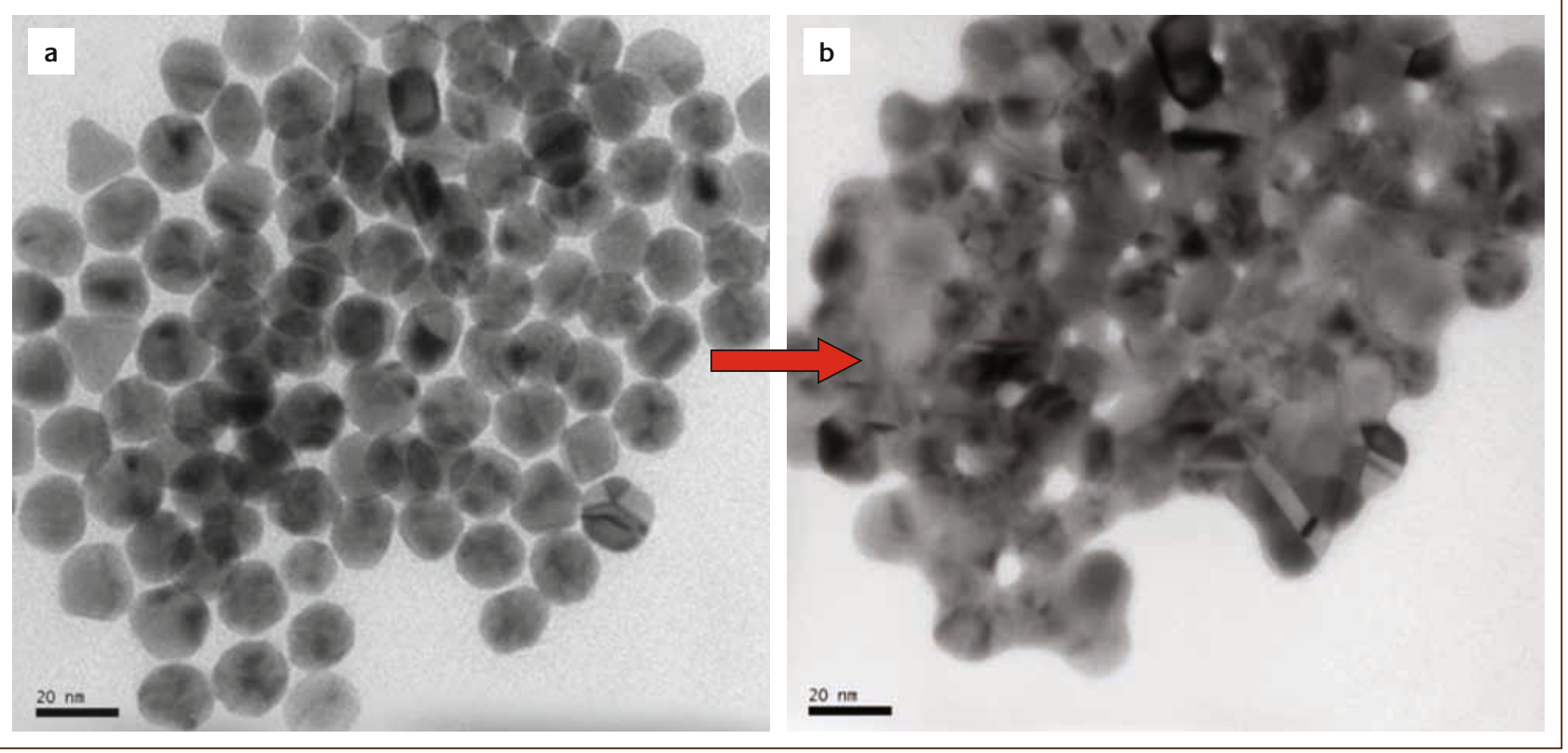

$15 \mathrm{~nm}$ particles supported on $\mathrm{Si}_{3} \mathrm{~N}_{4}$ before and after sintering [for 10 minutes at $250 \pm 20^{\circ} \mathrm{C}$ in an annular TEM heating stage] showing classic densification behavior

also been modified slightly. The initial skewed distribution has become more Gaussian in character because of the more rapid sintering of the very smallest particles as compared to the larger ones, due to their greater melting point depression (as discussed later). Similar coarsening behavior was also observed for the 3, 4, 5 and $8 \mathrm{~nm}$ nanoparticle samples on $\mathrm{Si}_{3} \mathrm{~N}_{4}$ membranes.

For the larger particles with a nominal size of $15 \mathrm{~nm}$, densification, whereby the particle centers move closer to each other, was observed during sintering on $\mathrm{Si}_{3} \mathrm{~N}_{4}$ regardless of the heating method. Figure 4(a) shows a TEM micrograph of Au particles with a measured mean size before sintering of $\sim 17 \mathrm{~nm}$ (nominal $15 \mathrm{~nm}$ ), and Figure 4(b) shows the same region after 14 minutes of in-situ sintering. Shrinkage of the nanoparticle agglomerate, and a decrease in pore size (densification) with a small amount of concurrent grain growth, as seen in Figure 4(b), was typical in this sample following both in-situ and ex-situ sintering.

The densification behavior for the $17 \mathrm{~nm}$ case may be related to the continued presence at the sintering temperature of the acrylate ligands, which are more strongly bound to the gold surface. By way of contrast, the 2, 3, 4, 5 and $8 \mathrm{~nm}$ particles, which all coarsened, were capped with alkanethiol ligands, which our TGA analyses (Figure 2) confirm to be volatile at the sintering temperature. Another fact that should be considered is that the ratio of the particle radius, $\mathrm{R}$, to particle separation, $\mathrm{S}$, are also varying significantly (i.e. $1<\mathrm{R} / \mathrm{S}<8$ ) in the complete set of samples examined. In the regime where $\mathrm{R}$ and $\mathrm{S}$ are comparable $($ i.e. $\mathrm{R} / \mathrm{S}<4$ ) it may be difficult to get enough inter particle-particle contact to allow densification to proceed. Further systematic experiments are currently underway in which we are attempting to separate the effects of residual strongly bound ligands and the R/S ratio on the sintering mode observed.

Sintering was also induced locally in the nanoparticle arrays by condensing the $200 \mathrm{keV}$ electron beam generated from a LaB ${ }_{6}$ filament in a JEOL 2000FX TEM down to a 300nm diameter convergent spot, and observing the effects of the beam on the nanoparticle raft. The condensed beam, supplying a current density of $50 \mathrm{pA} / \mathrm{nm}^{2}$, was held for 1 minute after which the beam intensity was decreased to normal level and an image recorded. This process was repeated in order to build up a time-sequence of images that captured the various stages on the sintering process in action.

Samples heated by the convergent electron beam showed sintering behavior very similar to that of the annular in-situ TEM heating stage, however, only within the local region affected by the high intensity beam. This similarity in sintering behavior is reasonable if one considers the likely interactions of the high incident electrons with the nanoparticle arrays supported on a $\mathrm{Si}_{3} \mathrm{~N}_{4}$ membrane. The nanoparticles are not in particularly good thermal contact with $\mathrm{Si}_{3} \mathrm{~N}_{4}$ membrane or each other, hence their temperature is likely to increase significantly by phonon excitation during electron beam irradiation, although it is very difficult to measure or estimate the precise temperature reached. The gold cores will not suffer significant knock-on damage under our illumination conditions, but it is highly probable that the ligands will suffer some radiolysis damage which would contribute to chain scission and eventual ligand desorption.

An advantage of the electron beam irradiation heating method was that it conveniently allowed a detailed evolutionary history of particle growth during sintering to be 


\section{Figure 5}
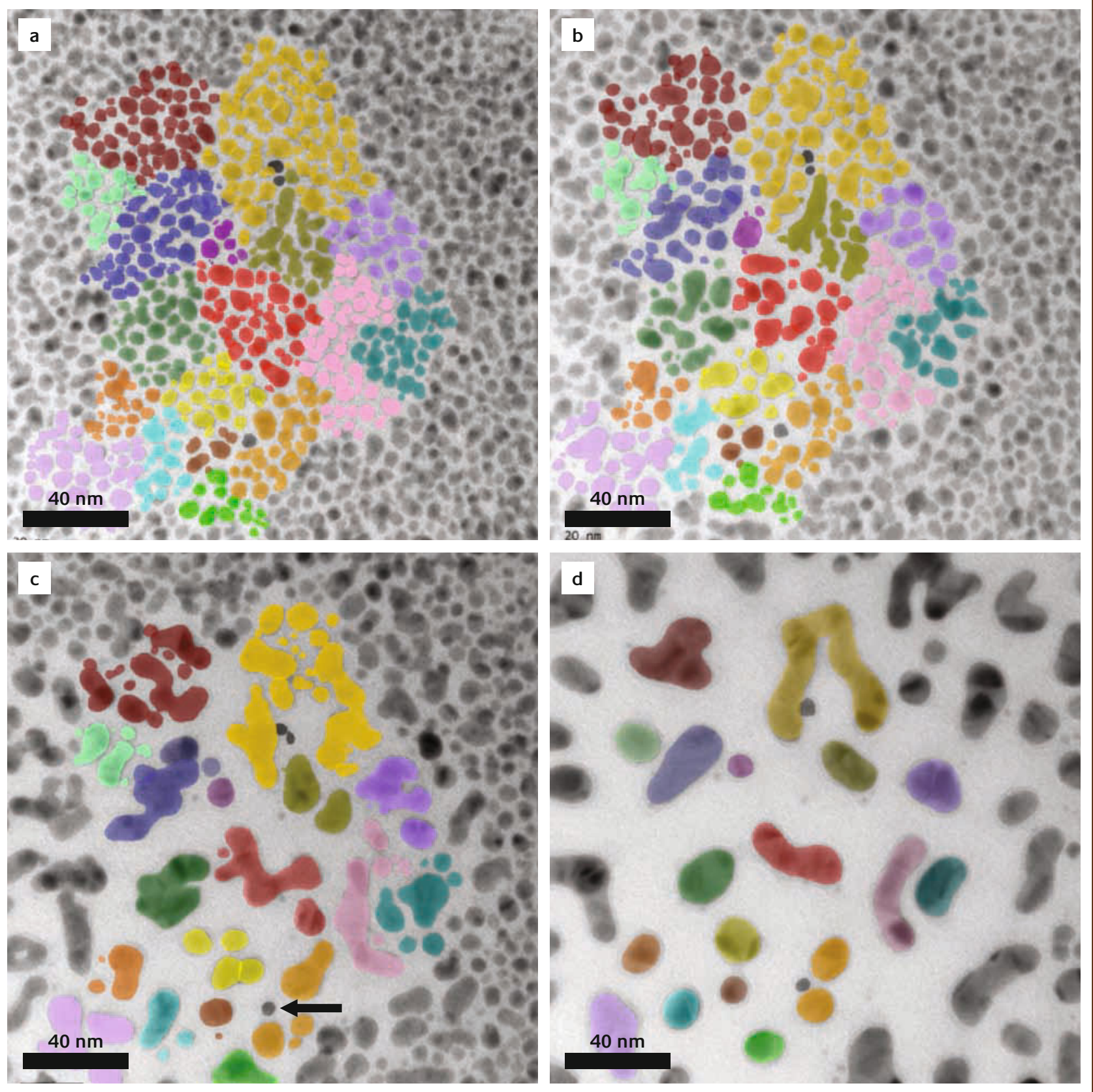

Sequence of micrographs showing the in-situ coarsening behavior of the $3 \mathrm{~nm}$ particle preparation supported on a $\mathrm{Si}_{3} \mathrm{~N}_{4}$ membrane. The images, which have been false colored to highlight nanoparticle trajectories, were captured after (a) 1 min, (b) 8 min, (c) 18 min and (d) 40 min of electron beam exposure [to a 300nm diameter spot with a current density of 50pA/nm²]

recorded. For example, Figure 5 shows a time sequence of images showing the coarsening behavior of the $3 \mathrm{~nm}$ particle preparation. Color coding has been used in Figures 5(a), (b) and (c) to highlight those particles which coalesce by surface diffusion and coarsen to the final particle configuration seen in Figure 5(d). Over the 40 minute beam exposure time of the experiment, all the particles (typically 40-80) shaded a particular color in an area of $\sim 400 \mathrm{~nm}^{2}$ are seen to coarsen into large single particles surrounded by a significant denuded zone. Considerable nanoparticle mobility was observed in such sequences, particularly in the early stages of the process where the particle mass was lowest.
Figure 6 shows a plot of mean particle size versus time derived from an irradiated region initially having about 2000 particles of $\sim 3 \mathrm{~nm}$ mean size. Coarsening progressed to reach a maximum projected mean diameter of $17 \mathrm{~nm}$ after 20 minutes of in-situ sintering, and then decreased in mean diameter to $14 \mathrm{~nm}$ after $\sim 50$ minutes. The decrease in diameter, assuming the particle volume remained constant, suggests that the particles were de-wetting the $\mathrm{Si}_{3} \mathrm{~N}_{4}$ surface and becoming more spherical.

Occasionally some particles in the images (e.g. see the arrowed particle in Fig 5(c)) appear to remain unchanged while all those around are consumed by neighboring growing 


\section{Figure 6}

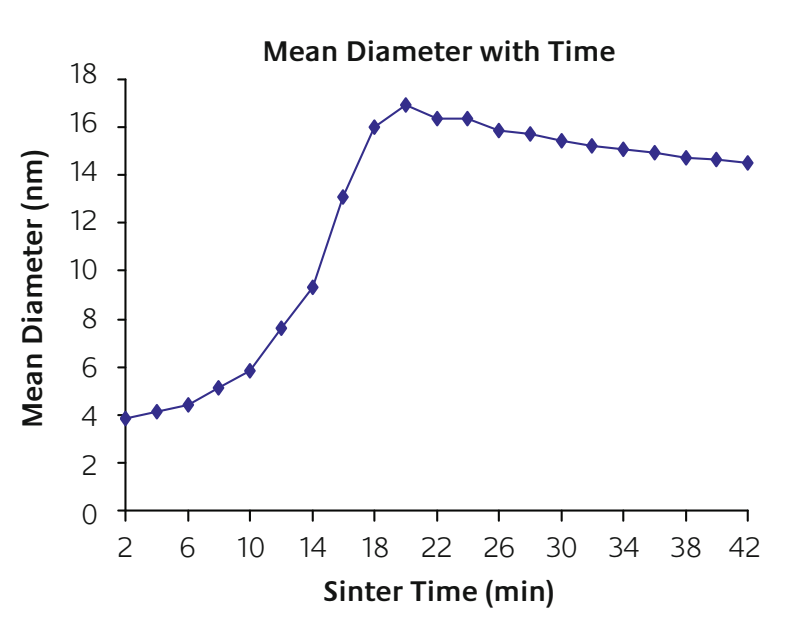

Plot of mean particle diameter with in-situ sinter time for particles with a 3nm starting size grains during sintering. These are thought to be a small population of particles which are located on the reverse side of the support film that have relatively few neighbors with which to interact.

Figure 7 shows a time sequence of images showing the detailed densification behavior under electron beam irradiation of the $15 \mathrm{~nm}$ particle preparation over a period of 56 minutes. The particle perimeters have been outlined in red for clarity, and it is apparent that the length of periphery and pore volume decrease progressively with sintering time. It is also clear, particularly in Figs 7(c) and (d) that recrystallization and grain growth phenomena are also occurring during densification.

Ex-situ sintering was performed by placing the membrane/ nanoparticle sample, mounted in a TEM specimen holder, into an $\mathrm{O}_{2}(25 \%)-A r$ plasma for two minutes. Samples were then returned to the JEOL 2000FX TEM for imaging. In contrast, to the behavior shown in Figure 3(a) and (b), the

\section{Figure 7}
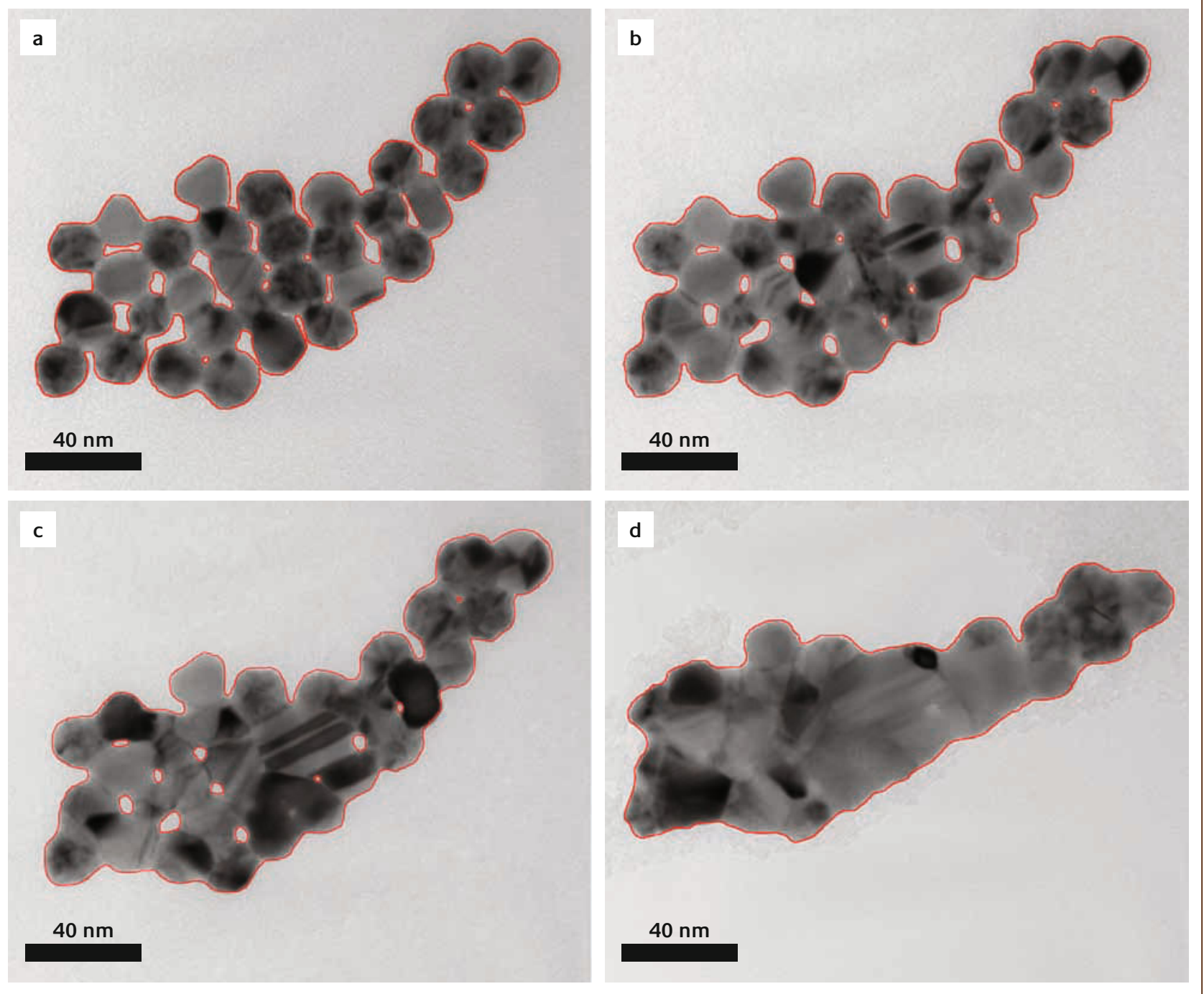

Sequence of micrographs showing the in-situ densification behavior of the $15 \mathrm{~nm}$ particle preparation supported on a $\mathrm{Si}_{3} \mathrm{~N}_{4}$ membrane. The images were captured after (a) $1 \mathrm{~min}$, (b) $20 \mathrm{~min}$, (c) $32 \mathrm{~min}$ and (d) 56 min of electron beam exposure [to a 300 $\mathrm{nm}$ diameter spot with a current density of $\left.50 \mathrm{pA} / \mathrm{nm}^{2}\right]$ 


\section{Figure 8}
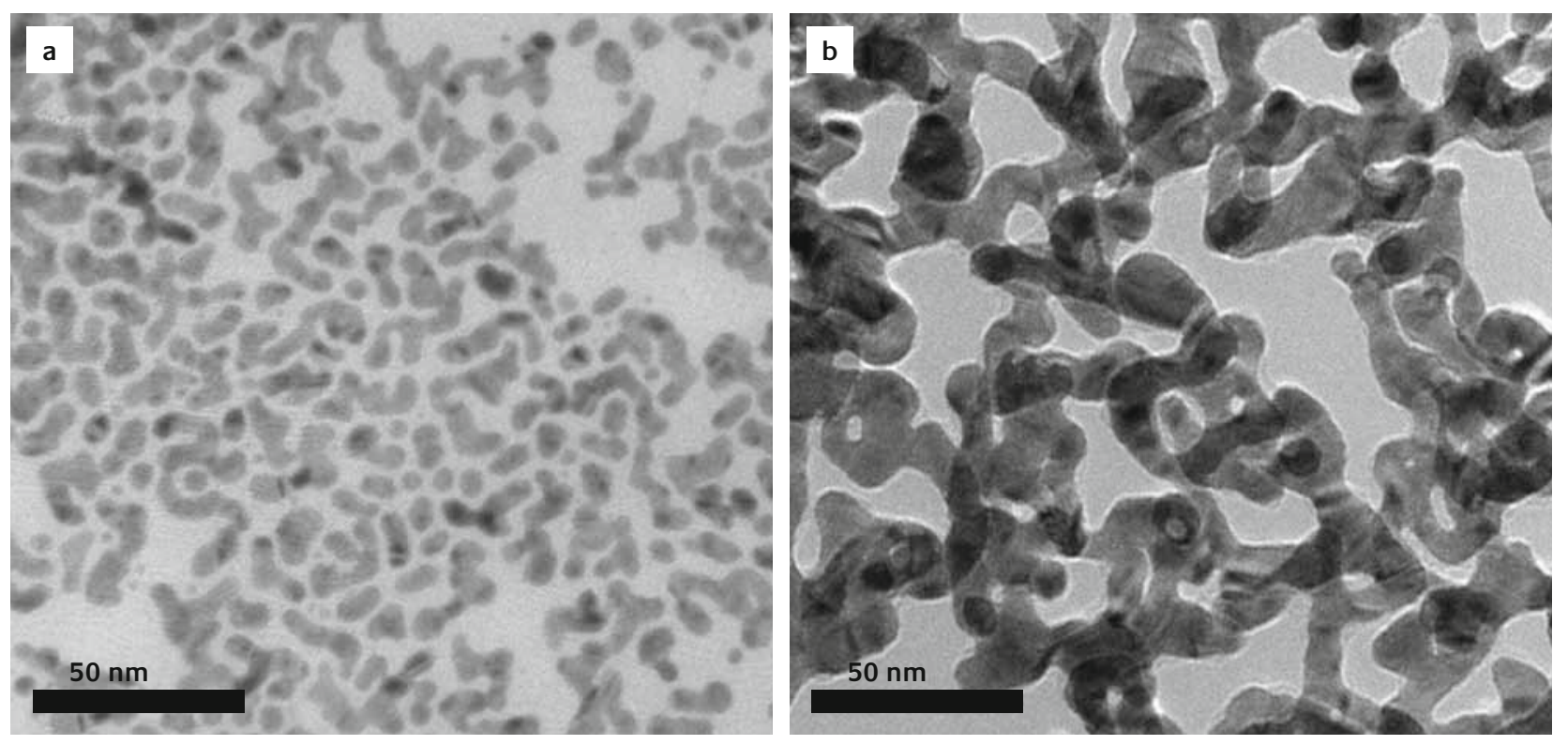

Rod or wire-like morphologies resulting from a rapid ex-situ oxygen/argon plasma sintering treatment of (a) the nominal $2 \mathrm{~nm}$ and (b) $5 \mathrm{~nm}$ preparations supported on $\mathrm{Si}_{3} \mathrm{~N}_{4}$ membranes

2-nm particles rapidly sintered under oxygen-argon plasma conditions and had a final structure that differed greatly in appearance from the in-situ slow sintered sample. As can be seen from Figure 8(a) neighboring particles have connected up to form interlaced rod-type structures. Interestingly the diameter of the rods is relatively uniform at about $5 \mathrm{~nm}$ and the structures show relatively little branching. It is also apparent that the $\mathrm{Au}$ seems to be wetting the $\mathrm{Si}_{3} \mathrm{~N}_{4}$ substrate surface. Figure 8 (b) shows that when the $5 \mathrm{~nm}$ starting material is rapidly plasma sintered in the same manner, the resulting structure is much more connected and web-like, with a typical fiber thickness of about $10 \mathrm{~nm}$. The rapid-thermal sintering of nanoparticle arrays and lines on $\mathrm{Si}_{3} \mathrm{~N}_{4}$ is being investigated further as an efficient method for the fabrication of nanopatterns and nanowires.

The effect of rapid thermal sintering in promoting an interconnected structure can be qualitatively understood by referring to Figure 9. An interconnected microstructure is favored when densification transport mechanisms (e.g. grain boundary diffusion) are rapid relative to coarsening transport mechanisms (e.g. surface diffusion). If the activation energy for densification is significantly greater than that for coarsening (which is consistent with the measured values for grain boundary and surface diffusion in gold), then a rapid heat up to a high enough temperature, such as that encouraged by plasma heating, will promote conditions favorable for densification relative to coarsening.

Classic experiments by Buffat and Borel [16,17] demonstrated that the melting temperature of Au particles decreases dramatically as the particle size decreases below $10 \mathrm{~nm}$. The strong dependence of Au melting point with

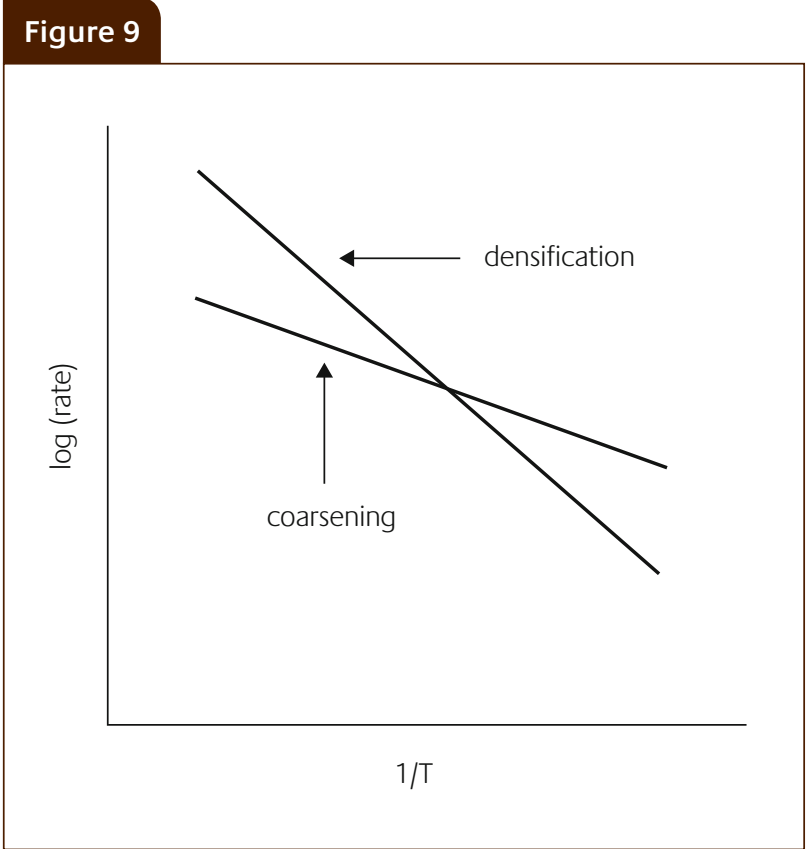

Schematic of the expected variation of coarsening and densification rate as a function of temperature. Densification is the preferred result of sintering at very high heating rates

particle diameter, as calculated from the Buffat and Borel model [17], is shown in Figure 10. By implication, sub-10 nmsized Au particles should readily sinter at temperatures much less than that required for larger particles. In fact, molecular dynamics simulations of nanoparticle sintering indicate that the mechanisms and kinetics differ significantly from micronsized particle sintering [25]. To test whether sufficient driving 


\section{Figure 10}

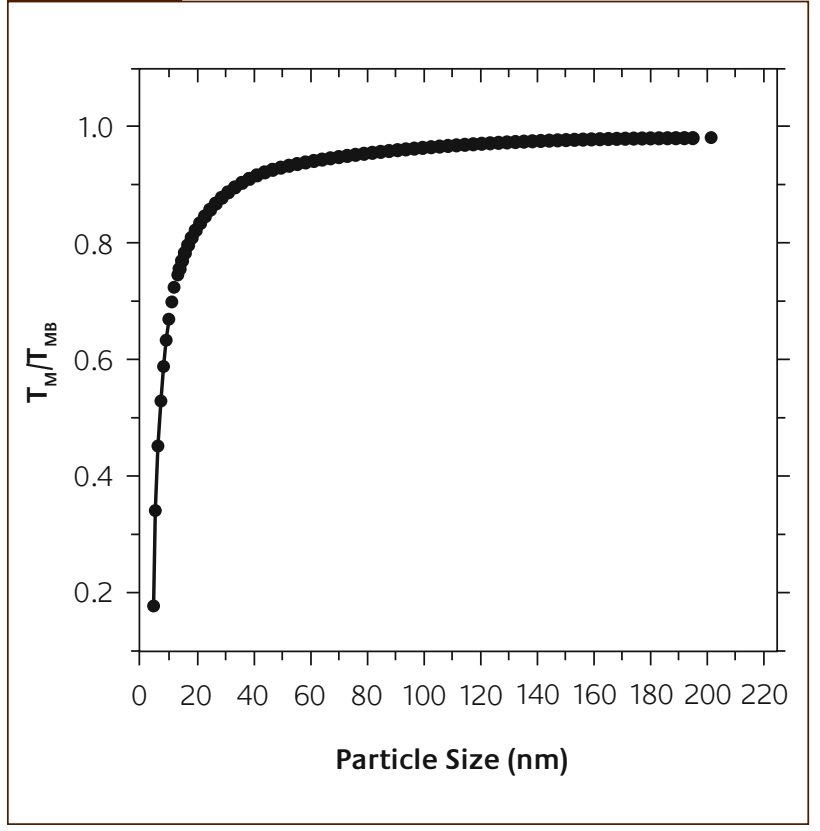

Calculated melting point depression (expressed as the ratio of nanoparticle melting temperature, $T_{M}$, to the melting point of bulk $\mathrm{Au}$, $T_{M B}$ ) as a function of particle diameter

\section{Figure 11}

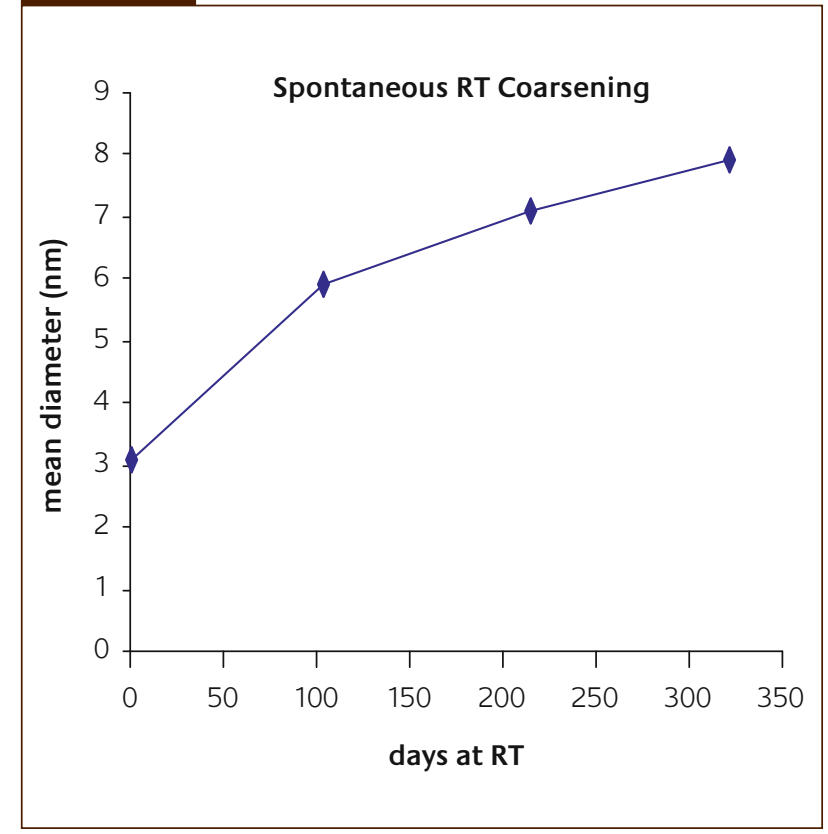

Plot of mean particle size as a function of room temperature $\left(23 \pm 2^{\circ} \mathrm{C}\right)$ sintering time for a dried 3nm Au sample

\section{Table 1}

Summary of room temperature sintering data for different starting particle sizes

\begin{tabular}{lcccc}
$\begin{array}{l}\text { Average Particle } \\
\text { Size at Start }\end{array}$ & $\begin{array}{c}\text { Starting } \\
\text { Areal Density }\end{array}$ & $\begin{array}{c}\text { Sample } \\
\text { Age }\end{array}$ & $\begin{array}{c}\text { End Areal } \\
\text { Density }\end{array}$ & $\begin{array}{c}\text { Average Particle } \\
\text { Size at End }\end{array}$ \\
\hline$(n m)$ & $\left(/ 10^{4} \mathrm{~nm}^{2}\right)$ & $($ days & $\left(/ 10^{4} \mathrm{~nm}^{2}\right)$ & $(\mathrm{nm})$ \\
2 & 480 & 214 & 29 & 7 \\
3 & 432 & 147 & 67 & 7 \\
4 & 396 & 154 & 336 & 5 \\
5 & 201 & 151 & 200 & 15 \\
15 & 37 & 147 & 37 & 5 \\
\hline
\end{tabular}

force and mobility exist for nanoparticles to sinter at room temperature, a set of samples were deposited onto a $\mathrm{Si}_{3} \mathrm{~N}_{4}$ substrate and stored under controlled ambient conditions at $23 \pm 2^{\circ} \mathrm{C}$. These nanoparticle arrays were periodically observed by transmission electron microscopy over the course of one year. Other than periodic observation in a JEOL 2000FX TEM, these samples experienced no post-preparation processing.

Images of the $3 \mathrm{~nm}$ sample were recorded and mean particle size measured every $\sim 100$ days over a period of 300 days. A plot of mean size versus days since deposition (Figure 11) reveals a continuous increase in mean particle size, and a decrease in coarsening rate, with time. Table 1 shows that an obvious coarsening was observed in the $2 \mathrm{~nm}$ sample as well, but samples with an initial mean particle size larger than $5 \mathrm{~nm}$ exhibited no change in size or areal particle density over 300 days. The $4 \mathrm{~nm}$ sample showed a very slight decrease in areal particle density, but no significant change in mean particle size. That these observations were due to spontaneous room-temperature sintering and not by interaction with the electron beam was evidenced by the fact that all areas of each sample showed the same stage of evolution over time. Another interesting feature that can be deduced from Table 1 is that in those samples which do exhibit room temperature sintering, particle growth ceases at around $7 \mathrm{~nm}$ in diameter. This is presumably because the melting point of the particle has now increased to a point where surface diffusion has become insufficient to maintain growth at room temperature. Furthermore, these room temperature sintering results imply that the dodecane-thiol protective ligand shell on the 2 and $3 \mathrm{~nm}$ Au nanoparticles must have been more significantly compromised than for the corresponding 4, 5 and $8 \mathrm{~nm}$ particles. 


\section{Conclusions}

This work has allowed us to gain a first overview of the factors that affect the sintering of Au nanoparticles. We have shown that arrays of smaller Au particles (2-8 nm) exhibit a fundamentally different sintering behavior on $\mathrm{Si}_{3} \mathrm{~N}_{4}$ substrates as compared to larger $15 \mathrm{~nm}$ particles (i.e. coarsening as compared to densification). This difference may be due to a combination of more strongly bound ligands and a larger particle radius to particle separation (R/S) for the $15 \mathrm{~nm}$ particles. In addition, for the smaller nanoparticles, the rate at which the arrays are heated strongly influences the type of sintered morphology obtained, with slow heating giving rise to more spherical coarsened clusters and rapid heating resulting in highly interconnected string-like structures. We find also that Au nanoparticles below $4 \mathrm{~nm}$ in diameter can spontaneously sinter in the dried out state at room temperature over extended time periods, probably as a consequence of ligand destabilization and their depressed melting points. This room temperature sintering phenomena ceases however when the particle has grown to a size of about $7 \mathrm{~nm}$ suggesting that the size-dependant melting point of the material is an important factor to consider in this process. This phenomenon, although specific to $\mathrm{Si}_{3} \mathrm{~N}_{4}$ supports at present, could have far reaching consequences for the long-term stability of self-assembled devices constructed with sub-4 nm Au particles in which the device function depends on retaining the structural integrity of the individual particles over long time periods.

\section{Acknowledgements}

CIK and MPH would like to acknowledge the financial support of the NSF (grants\# DMI-0304180 and DMI-0457602) and the Pennsylvania Department of Community and Economic Development under contract \# 20-906-0009.

\section{About the authors}

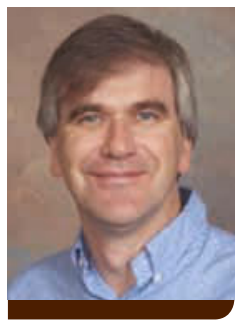

Chris Kiely is Director of the

Nanocharacterization Laboratory and a Professor of Materials Science and Engineering at Lehigh University, USA. His research expertise lies in the application and development of transmission electron microscopy techniques for the study of nanoscale features in materials. Particular areas of interest include catalyst materials, nanoparticle self-assembly, carbonaceous materials, and heteroepitaxial interface structures. He is also involved in microscopy technique development, and his current interests include X-Ray ultraMicroscopy (XuM) and aberration corrected Analytical Electron Microscopy (AEM).

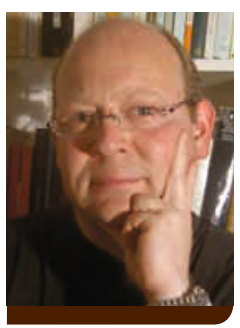

Mathias Brust is a Professor in the Department of Chemistry at the University of Liverpool, UK. He has worked with gold nanoparticles for over 15 years, and his most important contributions to the field relate to particles' synthesis and functionalization, and to nanostructure self-assembly. His current interests include the design and preparation of nanoparticle bioconjugates for diagnostics, controlled delivery and other purposes, for example to study and manipulate their interactions with living cells.

\section{References}

1 E.A. Dobisz, F.A. Buot and C.R.K. Marrian; A.S. Edelstein, R.D. Cammarata, eds., Institute of Physics Publishing, Bristol and Philadelphia, 1996

2 D. Eigler, Solid State Communications, 1998, 107, 711

3 R.D. Piner, J. Zhu, F. Xu, S. Hong and C.A. Mirkin, Science. 1999, 283, 661

4 A. Terfort, N. Bowden and G.M. Whitesides, Nature, 1997, 386, 162

5 N. Bowden, A. Terfort, J. Carbeck and G.M. Whitesides, Science. 1997, 276, 233

6 M. Brust and C.J. Kiely, Colloids and Surfaces. 2002, 202, 175

7 G. Schmid, Chem. Rev. 1992, 92, 1709

8 M. Brust, D. Bethell, D. Schiffrin and C.J. Kiely, Adv. Mater., 1995, 7, 795

9 C.B. Murray, C.R. Kagan and M.G. Bawendi, Science, 1995, 270, 1335

10 R.P. Andres, J.D. Bielefeld, J.I. Henderson, J.B. Janes, V.R. Kolungunta, C.P. Kubiak, W.J. Mahoney and R.G. Osifchin, Science, 1996, 273, 1690

11 Z.L. Wang, Adv. Mater., 1998, 10, 13

12 M. Brust, M. Walker, D. Bethell, D.J. Schiffrin and R. Whyman; J. Chem. Soc. Chem. Commun., 1994, 801

13 Y. Chen, R.E. Palmer and J.P. Wilcoxon, Langmuir, 2006, 22, 2851

14 C.J. Kiely, J. Fink, M. Brust, D. Bethell and D.J. Schiffrin, Nature, 1998, 396, 444 
15

T.O. Hutchinson, Y.P. Liu, C. Kiely, C.J. Kiely and M. Brust, Adv. Mats., 2001, 13,1800

16 P. Buffat and J-P. Borel, Phys. Rev. A, 1975, 13, 2287

17 P. Buffat, Thin Solid Films, 1976, 32, 283

18 P.R. Couchman and W.A. Jesser, Nature, 1977, 269, 481

19 J.P. Borel, Surface Science, 1981, 106, 1

20 R.R. Vanfleet and J.M. Mochel, Surface Science, 1995, 341, 40

21 S. lijima and T. Ichi, Phys. Rev. Letts., 1986, 36, 616

22 J.R. Sambles, Proc. Roy. Soc. A, 1971, 325, 339

23. M. Flueli, P.A. Buffat and J.P. Borel, Surface Science, 1988, 202, 343

24. H.B. Liu, M. Jose-Yacaman, R. Perez and J.A. Ascensio, Appl. Phys, A., 2003, 77, 63

25 P. Zeng, S. Zajac, P.C. Clapp and J.A. Rifkin, Mat. Sci. and Eng,. 1998, A252, 301

26 K. Nakaso, M. Shimada, K. Okuyama and K. Deppert, J. Aerosol Sci, 2002, 33, 1061
27 S. Arcidiacono, N.R. Bieri, D. Poulikakos and C.P. Grigoropoulos, J. Multiphase Flow, 2004, 30, 70

28 T. Hawa and M.R. Zacharia, J. Aerosol Sci., 2006, 37, 1

29 L.J. Lewis, P. Jensen and J.L. Barrat, Phys. Rev. B, 1997, 56, 2248

30 M.J. Hostetler, J.E. Wingate, C-J. Zhong, J.E Harris, R.W. Vachet, M.R Clark, J.D. Londono, S.J. Green, JJ. Stokes, G.D. Wignall, G.L.Glish, M.D. Porter, N.D Evans, and R.W Murray, Langmuir, 1998, 14, 17

31 I. Hussain, M. Brust, A. Papworth and A.I. Cooper, Langmuir, 2003, 19, 4831

32 D.V. Leff, L. Brandt and J.R. Heath, Langmuir, 1996, 12, 4723

33 R.H. Terrill, T.A. Postlethwaite, C. Chen, J.E. Hutchison, C. Poon, A. Tarzis, A. Chen, M.R. Clark, C.S. Johnson, E.T. Samulski, J.M. Desimone and R.W. Murray, Abstr. Papers Am. Chem. Soc., 1995, 210, 380

34 M.K. Corbiere, N.S. Cameron and R.B. Lennox, Langmuir, 2004, 20, 2867 